\title{
Characterization of North American Ginseng Rust-Spot and the Effects of Ethephon
}

\author{
Cindy Campeau*, John T.A. Proctor*\#, Dennis P. Murr*, and Jan Schooley** \\ *Department of Plant Agriculture, University of Guelph, Guelph, Ontario, N1G 2W1, Canada \\ **Ontario Ministry of Agriculture and Food, Simcoe, Ontario, N3Y 4N5, Canada
}

(Received September 21, 2003, Accepted December 3, 2003)

\begin{abstract}
Rust-spot on North American ginseng roots (Panax quinquefolius L.) is considered a physiological, not a pathological disorder. Ginseng rust-spot starts as an orange spot on the surface of the root and may spread forming a sunken, round to irregular lesion, $\approx 5 \mathrm{~mm}$ in diameter. Pieces of root, $\approx 7 \mathrm{~mm}$ in length and containing a rust-spotted lesion, were embedded in agar and sectioned using a vibratome. These sections and hand sections, cut with a two-sided razor blade, were examined using fluorescence microscopy. The 4-5 cell layers of the periderm were destroyed in the area of the lesion and orange substances were deposited in and around the lesion. Sections stained with vanillin- $\mathrm{HCl}$ and viewed using bright field microscopy confirmed that the orange substances were phenolic compounds. Scanning electron microscopy showed that the periderm had pulled away from the root, or was completely destroyed, in the area of the lesion. The smooth surface of the lesion indicates the deposition of phenolic compounds in surrounding cells as a wound response. Roots sprayed or dipped in ethephon $\left(1500 \mathrm{mg} \cdot \mathrm{L}^{-1}\right)$ developed rust-spots, more so at $21 \pm 2^{\circ} \mathrm{C}$ than at $3 \pm 0.2^{\circ} \mathrm{C}$. Roots held at $21 \pm 2^{\circ} \mathrm{C}$ were yellowish and developed white cell proliferations. Comparable control roots also developed rust-spots likely due to the high undecomposed organic matter content of the incubation soilless mix.
\end{abstract}

Key words : Panax quinquefoitus, periderm, rusty root, phenolics

\section{INTRODUCTION}

Rusty root of ginseng has become more prevalent in ginseng gardens worldwide. The most confusing aspect of rusty root is that both a fungal disease and a physiological disorder are referred to as rusty root. This study focuses on the physiological disorder and, to eliminate any confusion, will be referred to as ginseng rust-spot. The symptoms of rusty root are dry, orange-brown areas occurring randomly on the surface of the root ${ }^{1)}$ and are likely caused by the fungus Cylindrocarpon destructans (Zinnsmeister) Scholten. ${ }^{2)}$ This fungus is one of the causal agents of disappearing root rot of ginseng that results in severe economic losses due to the destruction of entire roots. ${ }^{1-4)}$

Plant pathologists often group rusty root and disappearing root rot together based on their speculated causal agent but are unable to explain why this fungus causes such a wide range of symptoms. Parke and Shotwell ${ }^{1)}$ reported

\footnotetext{
\# To whom correspondence should be addressed.

(Tel) +519-824-4120, ext. 53446; (Fax) +519-767-0755

(E-mail) jtprocto@ugouelph.ca
}

that the fungi Cylindrocarpon and Fusarium were often found in association with rusty root but were not its cause. They suggested that rusty root is a result of the combination of biological and nutritional factors.

The symptoms of rusty root start out similar to ginseng rust-spot but eventually result in the destruction of the affected root parts. Ginseng rust-spot does not affect the overall yield but decreases root quality and, therefore, the economic value of the root. Work with Asian ginseng (Panax ginseng C.A. Meyer) showed that the periderm of affected roots needs to be removed before marketing, therefore decreasing the quality of the roots by 2-3 grades. ${ }^{5)}$ Symptoms of ginseng rust-spot are induced by a number of environmental factors. Yingping et al. ${ }^{5)}$ determined that excessive $\mathrm{Fe}^{2+}$, low boron and high undecomposed organic matter in the soil may all contribute to ginseng rust-spot. In our earlier work $^{6)}$ the mineral elements $\mathrm{N}, \mathrm{P}, \mathrm{Ca}, \mathrm{Mg}, \mathrm{Zn}$, $\mathrm{Mn}$, and $\mathrm{Fe}$ were higher in rust-spotted tissue than in healthy tissue. Lee et al. ${ }^{7}$ ) also showed that $\mathrm{Fe}, \mathrm{Na}$ and $\mathrm{Al}$ were higher in rusty root than in healthy tissue. Soil temperatures below $-4^{\circ} \mathrm{C}$ may also cause ginseng rust-spot (Dr. Yun-Hyun Yu, personal communication). 
Anatomical studies of North American ginseng roots affected by ginseng rust-spot have not been conducted. Previous anatomical studies have focused on the structure of healthy $\mathrm{Asian}^{8)}$ and North American ${ }^{9)}$ ginseng roots. A detailed investigation of the tissues affected by ginseng rust-spot may lead to a better understanding of the disorder.

Symptoms similar to those found with ginseng rust-spot, occur on carrot ${ }^{10)}$ and on lettuce leaves. Russet spotting on lettuce is a physiological disorder first identified by Link and Cardner ${ }^{11)}$ as the occurrence of small brown spots and streaks along the midribs of the leaves. The browning observed in russet spotting of lettuce is due to the oxidation of phenolic compounds by polyphenol oxidase. ${ }^{12-14)}$ The development of russet spots on lettuce can be induced by exposure to low concentrations of exogenous ethylene. ${ }^{15)}$ In our earlier work with ginseng rust-spot ${ }^{6)}$ we showed that the phenolic content of rust-spotted periderm tissue was $53 \%$ higher than adjacent non-rusted tissue ( 4.67 v.s. $3.05 \mathrm{mg} \cdot \mathrm{g}^{-1}$ dry wt as gallic acid equivalents). Lee, ${ }^{16)}$ working with Asian ginseng, reported a higher content of phenolic compounds in the root epidermis of ginseng lines with a high degree of rusty root than those lines with a low degree of rusty root. Further, he suggested that the content of phenolic compounds might be a marker for selecting rusty root tolerance.

Ethephon, (2-chloroethyl) phosphonic acid, is a plant growth regulator (PGR) that stimulates flower abscission in ginseng and increases root yield. ${ }^{17,18)}$ The use of ethephon to remove ginseng inflorescences would decrease production costs significantly by eliminating the cost of labor $(\$ 2500$ per hectare) to manually remove inflorescences ${ }^{19)}$. In order for ethephon to be registered for use on ginseng its effects on ginseng plants and particularly roots need to be investigated in detail. It is essential that the use of ethephon does not cause, or aggravate, the symptoms of ginseng rust-spot. The objectives of this study were to i) characterize ginseng rust-spots by using various microscopic techniques; ii) investigate if phenolic compounds are involved in the browning observed; iii) determine if ethylene produced from the breakdown of ethephon can induce ginseng rust-spot.

\section{MATERIALS AND METHODS}

Roots for all experiments described here were obtained from 3-year-old Ontario commercial gardens of Panax quinquefolius (North American ginseng) and were stored at $3 \pm 0.2^{\circ} \mathrm{C}$ until needed.

\section{Anatomical Studies. Hand Sections}

Sections of lateral roots containing rust-spots were cut with a two-sided razor blade and immediately mounted on a slide, in water. The sections were stained with vanillin$\mathrm{HCl}$ to locate phenolics ${ }^{20)}$. A red color is produced when aldehyde groups in the vanillin condense with phenols in the tissue. The coverslip was sealed using nail polish to reduce the amount of fumes coming from the slide. Sections were viewed using a Carl Zeiss JENA light microscope. Images were created using a Sony digital camera and Northern Eclipse software. Final plates were created using Corel Draw.

(1) Vibratome

Sections about $3 \mathrm{~mm}$ in length and width, containing all or part of a rust-spot, were cut from main and lateral roots and placed in water. Agar (6\%) was poured into plastic boats, $30 \mathrm{~mm} \times 15 \mathrm{~mm} \times 10 \mathrm{~mm}$, and one root section was placed in each boat. The sections were pushed to the bottom of the boat so that the area to be sectioned was flush with the bottom. The boats were refrigerated $\left(5 \pm 2^{\circ} \mathrm{C}\right)$ for 10 min to set the agar. An agar block, containing a root sample, was removed from the boat and placed on the motherboard of the DSK Microslider Vibratome. Sections 50 to $60 \mu \mathrm{m}$ thick were cut and viewed under blue light using the same microscope and digital camera described for the hand sections. The filter used for blue excitation was 450-490 EX, 520 beamsplitter and 520 LP emitter. Phenolic deposits autofluoresce under blue light because they absorb the short-wave length of light and re-emit it at a longer wavelength. ${ }^{21)}$

\section{(2) Scanning Electron Microscope (SEM)}

The protocol for preparation of samples for SEM followed the procedure used by Massicotte et al. $^{22)}$ Samples, about $3 \mathrm{~mm} \times 3 \mathrm{~mm}$, were fixed in glutaraldehyde overnight and then rinsed twice, for $10 \mathrm{~min}$ each time, in a phosphate buffer, $\mathrm{pH}$ 6.8. The buffer was made using a 1:1 ratio of $0.07 \mathrm{M} \mathrm{KH}_{2} \mathrm{PO}_{4}$ and $0.07 \mathrm{M}$ of $\mathrm{Na}_{2} \mathrm{HPO}_{4} \cdot 7 \mathrm{H}_{2} \mathrm{O}$. Half of the samples were placed in liquid nitrogen and fractured by placing a one-sided razor blade on the sample and hitting the blade with a metal file. The rest of the samples were cut into smaller pieces using a one-sided razor blade. Excess fixative and buffer were removed and the samples were gradually dehydrated in a graded ethanol series of $70 \%$, $90 \%, 95 \%$ and $100 \%$. Each step was left for $15 \mathrm{~min}$. The 95\% and $100 \%$ steps were repeated for another $15 \mathrm{~min}$ and then the tissue was left in a final change of $100 \%$ ethanol for one hr. The dehydrated samples were then critical point dried using carbon dioxide as the transition fluid. Once all the alcohol was removed the samples were mounted, using two-sided tape, on the metal pegs and the pegs were stored in a dessicator for the remainder of the analysis. Samples 
were viewed using a Hitachi S-570 Scanning Electron Microscope and digital images were created using Voyager applications. Final plates were created using Photoshop.

\section{Root Bioassay. Ethephon Applied Directly to Roots}

Ginseng roots not containing rust-spots were selected for these experiments. Two sets of roots each were set up using the same eight treatments, with three roots per treatment. One set was stored at $3 \pm 0.2^{\circ} \mathrm{C}$ and the other at room temperature $\left(21 \pm 2^{\circ} \mathrm{C}\right)$. Roots for treatment 1 were placed in a plastic container for one min with enough deionized water to cover them. Roots for treatment 2 were sprayed to the drip point with deionized water. Roots in treatments 3, 4 and 5 were sprayed to the drip point with $1500 \mathrm{mg} \cdot \mathrm{L}^{-1}$ ethephon (Ethrel®. Rhone-Poulenc Canada Inc., Mississauga, Ontario). Roots for treatments 6,7 and 8 were clipped in $1500 \mathrm{mg} \cdot \mathrm{L}^{-1}$ ethephon for one min. After each treatment roots were placed on paper towels and allowed to air dry.

Roots were then placed in the appropriately labeled bags and covered with Pro-Mix-Bx (70\% peat, 20\% perlite, 10\% vermiculite and micronutrients) (Premier Horticulture Ltee., Riviere-du-Loup, Quebec). One set of 8 treatments was placed in a green plastic bin, covered with a plastic lid and placed at $3 \pm 0.2^{\circ} \mathrm{C}$. The other set was placed in a similar plastic bin, covered and kept at room temperature. Bags were checked on a daily basis and Pro-Mix-Bx was moistened as needed. Seven days after the set up of the experiment all treatments were examined for any changes and treatments 4 , 5,7 and 8 were treated a second time with $1500 \mathrm{mg} \cdot \mathrm{L}^{-1}$ ethephon. The roots were allowed to air dry and then placed back into their appropriate bags under the corresponding temperature. Fourteen days after the initial set up the roots were examined for any changes and roots in treatments 5 and 8 were treated again with $1500 \mathrm{mg} \cdot \mathrm{L}^{-1}$ ethephon. They were air dried, placed back in their bags and stored at the appropriate temperature. Twenty-one days after the start of the experiment the roats were removed from the bags, rinsed and final ratings and observations were made. The above experiment was carried out twice.

\section{RESULTS AND DISCUSSION}

\section{Anatomical Studies}

Ginseng rust-spot first appears as a small orange-brown spot on the surface of the root (Fig. 1A). The rust-spots occur randomly on the main and lateral roots, are sunken and round or irregular and are $\approx 5 \mathrm{~mm}$ in diam. The rustspots remain dry and may expand on the root surface. They may also penetrate deeper into the root affecting more cell
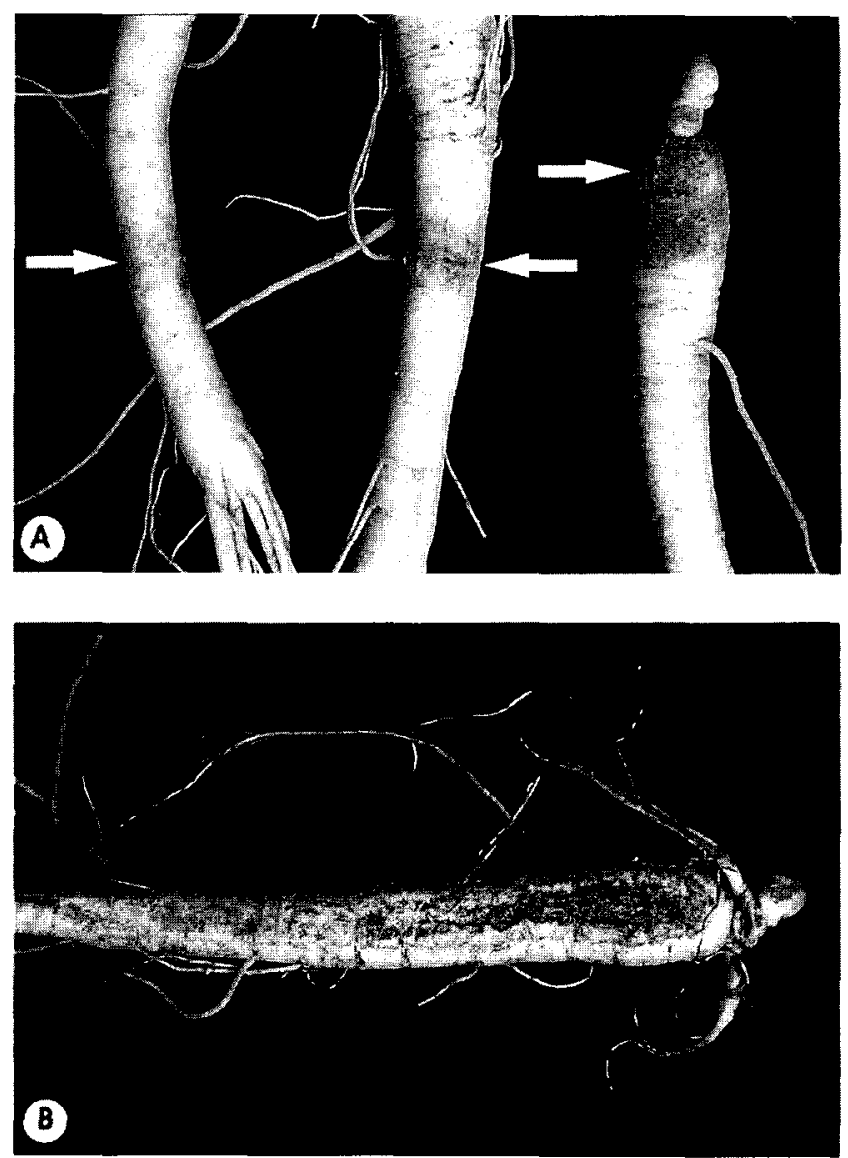

Fig. 1. A. Three-year-old North American ginseng roots showing the progression of the symptoms of rust-spot. The root on the left shows a rust-spot. The middle root shows the beginning of a lesion and the last root shows more severe symptoms. B. Orange discoloration on a root due to mechanical damage during harvest.

layers. The progression of rust-spot symptoms is shown in Fig. 1A. Parke and Shotwell ${ }^{1)}$ and Brammall ${ }^{2)}$ described "rusty root" as raised, reddish brown lesions that varied in size, and sometimes enlarged to surround and girdle the root. Brammall ${ }^{2}$ stated that the fungus Cylindrocarpon is the cause but Parke and Shotwell ${ }^{1)}$ reported that Cylindrocarpon and Fusarium are not always the cause even though they are often found in association with the spots.

Rust-spot is usually confined to the root surface (see below) but Parke and Shotwell ${ }^{1)}$ reported that rusty-tissue growth may progress slowly over one or more years, with the affected area falling off leaving rust coloured shallow scars surrounding the root. Roots affected may be rendered marketable through removal of the damaged tissue. Rustspotted roots are unlike those called "rusty root" caused by the fungus Cylindrocarpon which show lack of fibrous roots near the infected area, and disintegration of the core 
of the root leaving only the outer shell ${ }^{1,2)}$. Foliage on physiologically or pathologically challenged rusty roots may either show no discoloration if the stem is not infected, or may turn yellow or red during the season.

The characteristic orange color of rust-spot is sometimes observed on roots mechanically damaged during harvest (Fig. 1B). The induced coloration suggests leakage of metabolites, possibly phenolics (see below), and their subsequent oxidation. Cutting a notch in the root, and observing colour development over $24 \mathrm{hrs}$, can induce similar damage.

Typical rust-spots on 3-year-old North American ginseng roots were examined by the Pest Diagnostic Clinic (Laboratory Services, University of Guelph, Guelph, Ontario) for the presence of fungal or bacterial infection. No pathogenic microorganisms were found in association with the rustspots. However, the bacterium Pseudomonas marginalis was identified from some of the rust-spots. This bacterium has not been reported for ginseng but is known to cause pink eye of potato resulting in the development of superficial reddishbrown lesions on potato tubers ${ }^{23)}$. It is possible, however, that the wounding initially caused by rust-spot disorder may lead to secondary infection by microorganisms.

It seems likely that ginseng rust-spot described here, and rusty root caused by Cylindrocarpon destructans, are linked. Bonello and Pearce ${ }^{24)}$ and Matuo and Miyazawa ${ }^{25)}$ concluded that $C$. destructans is not considered highly pathogenic but a secondary invader, entering through wounds. Possibly the periderm tissue destruction of rust-spot in ginseng provides the necessary entry point for $C$. destructans. Once the fungus is established it is unlikely that the defensive barriers arising from the phellogen can exclude it, so cells and tissue are rapidly disrupted and die. The final result is dry, orange-brown areas typical of $C$. destructans damage. ${ }^{2)}$

Examination by fluorescence microscopy showed that the 4-5 layers of the periderm were destroyed in the area of the rust spot (Fig 2A). The affected area, and cells immediately surrounding the area, fluoresced orange, which is typical for phenolic compounds. This is in agreement with our earlier work ${ }^{6}$ where we reported high levels of phenolics in rust-spots. Anatomical studies on typical russet spots of lettuce showed that the epidermis and about 8 layers of mesophyll cells were affected. ${ }^{26)}$ In both lettuce and ginseng rust-spots the necrosis gradually progresses to the adjacent cells. Hand sections of ginseng roots, stained with vanillin$\mathrm{HCl}$, showed that the collapsed cells and those bordering that area were stained red thus confirming that the oxidation of phenolic compounds is responsible for the orangebrown color observed (Fig. 2B). Russet spotting of lettuce is induced during post-harvest storage by the presence of
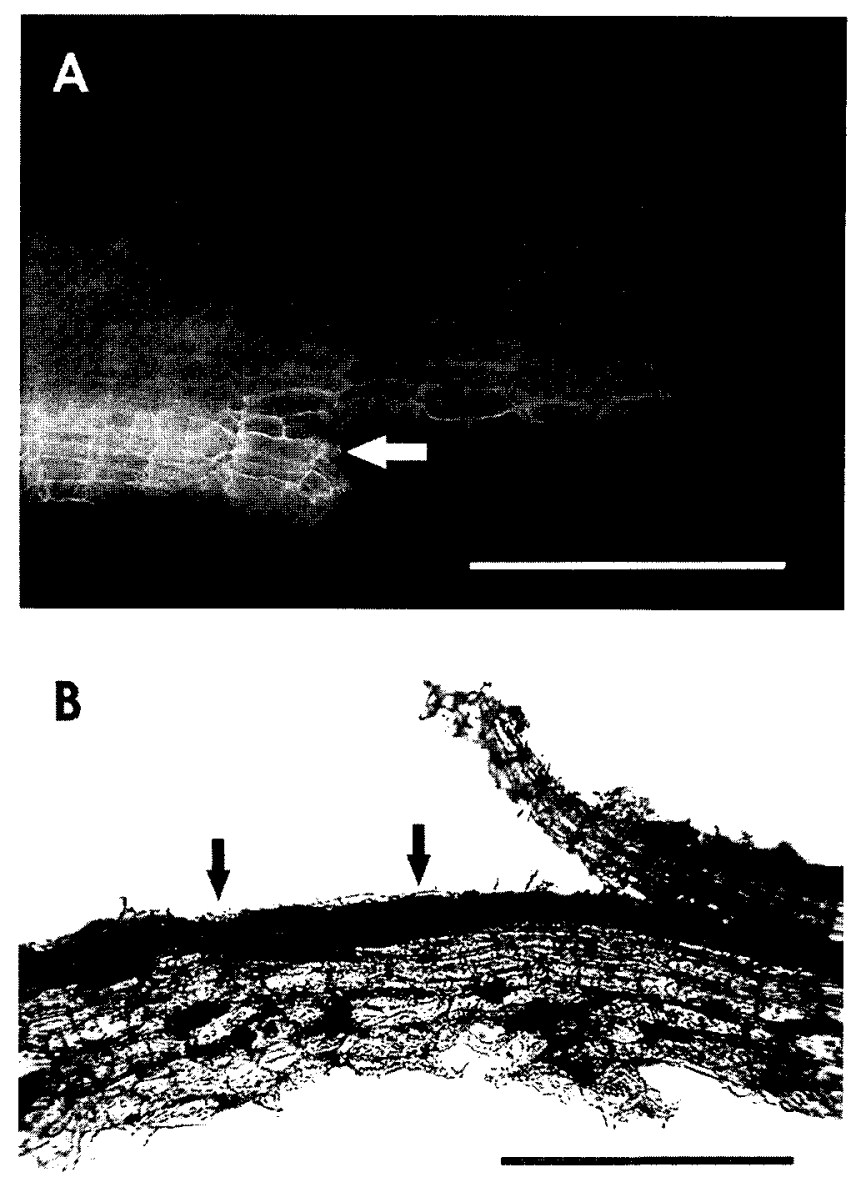

Fig. 2. A. An unstained cross-section of a 3-year-old North American ginseng lateral root, mounted in water and photographed under blue light using fluorescence microscopy. The periderm was completely destroyed in the area affected by ginseng rust-spot (arrow). A brown substance has been deposited in and around the lesion. Scale bar $=250 \mu \mathrm{m}$. B. A cross-section of a 3-year-old North Ameri-can ginseng main root, stained with vanillin- $\mathrm{HCl}$, mounted in water and viewed using bright field microscopy. The red-brown color visible around the lesion (arrows) indicates the presence of phenolic compounds. Scale bar $=250 \mu \mathrm{m}$.

ethylene resulting in an increase in phenolic production. ${ }^{13,27)}$ The possible role of ethylene on ginseng rust-spot is discussed below.

Further examination of rust-spot under SEM verified the collapse of the periderm in the lesion (Fig. 3A). The surface of the roots were also examined and it appeared that the rust-spot had a much smoother surface then the surrounding healthy tissue (Fig. 3B). It is possible that the smoothness of the rust-spot is due to the deposition of phenolic compounds as a wound response. The role of phenolics in defence against fungal pathogens has been reviewed ${ }^{28)}$. 

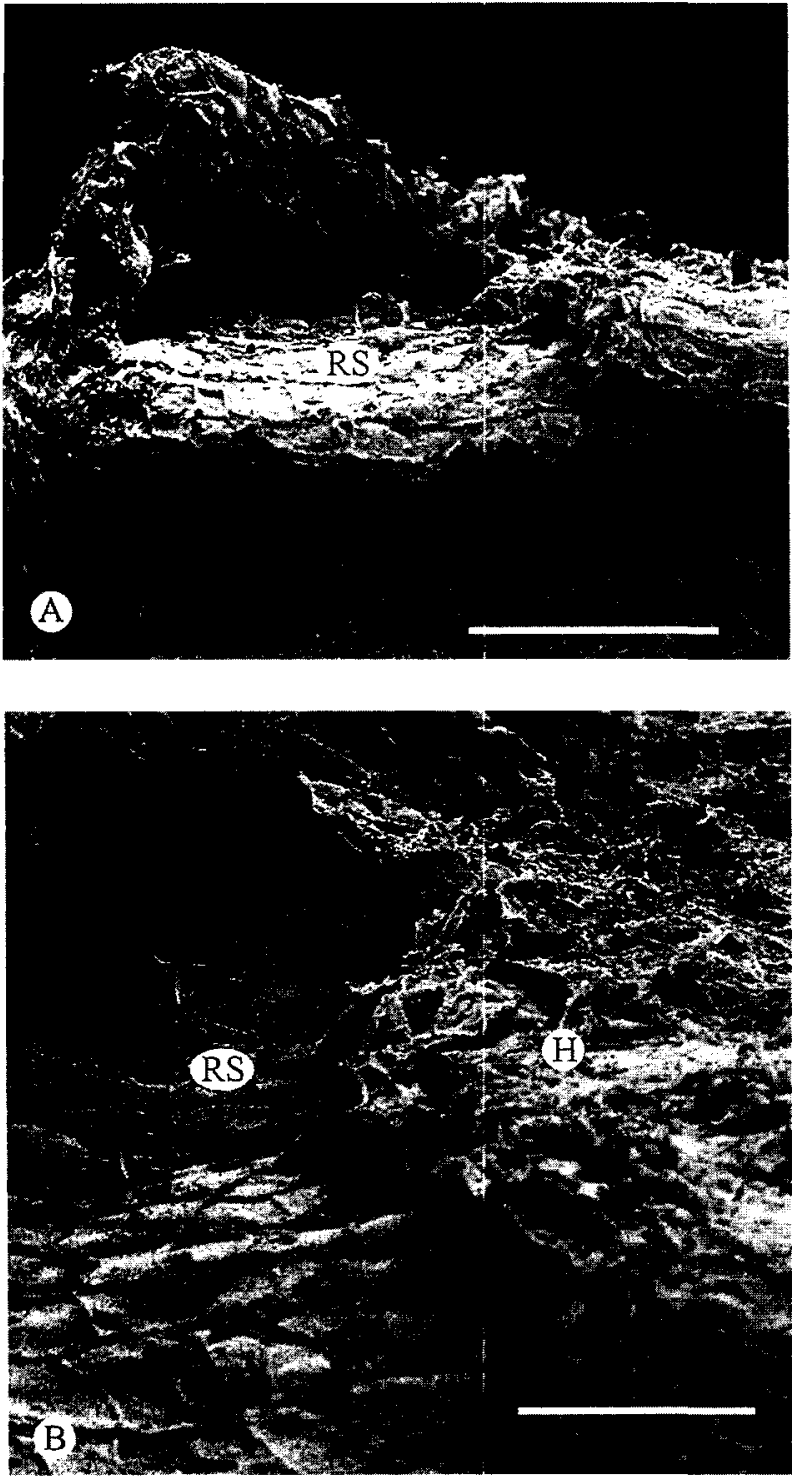

Fig. 3. A. A cross-section of a 3-year-old North American ginseng main root viewed using SEM. The periderm is destroyed in the area affected by ginseng rust-spot (RS). Scale bar= $250 \mu \mathrm{m}$. B. The surface of a similar main root viewed using SEM. The smooth, indented area on the left side is a rust spot (RS). The healthy tissue on the right $(\mathrm{H})$ has a more coarse appearance. Scale bar $=250 \mu \mathrm{m}$.

\section{Root Bioassay}

All roots treated with ethephon developed rust-spots and those stored at room temperature exhibited more severe symptoms (Fig. 4). There was no difference in the severity of the rust-spots between those roots treated once or multiple times with ethephon. There was also no difference between sprayed or dipped roots. The roots stored at room temperature had an overall yellow appearance and also

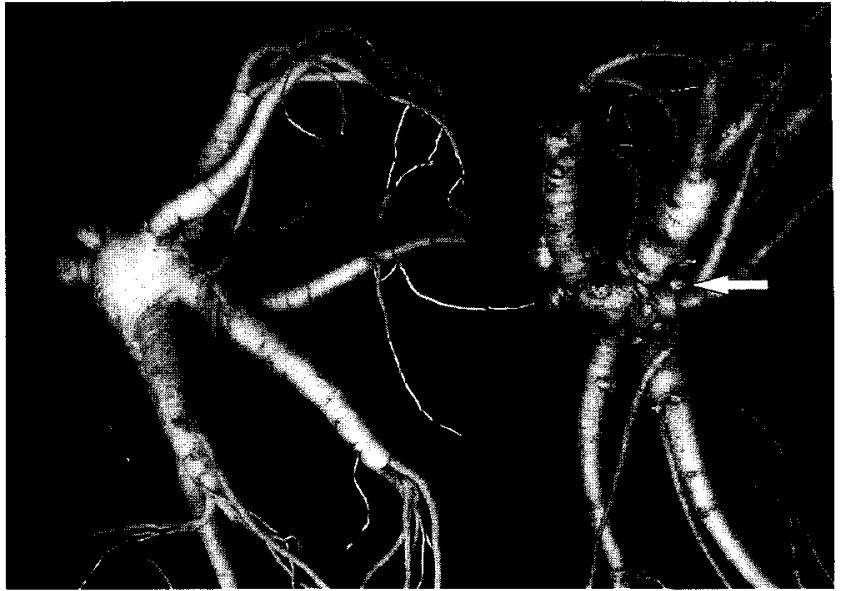

Fig. 4. Three-year-old North American ginseng roots treated with $1500 \mathrm{mg} \cdot \mathrm{L}^{-1}$ ethephon. The root on the left was stored at $3 \pm 0.2^{\circ} \mathrm{C}$ and the root on the right was stored at room temperature $\left(21 \pm 2^{\circ} \mathrm{C}\right)$. Both developed symptoms of rustspot but the symptoms were more severe at room temperature. The root on the right also developed cell proliferations (arrow).

developed white, tumour-like cankers due to cell proliferations near the surface (Fig. 4). Ethylene-induced cell proliferations are common ${ }^{29)}$ and are likely an indication of stress within the tissues.

The control roots at both temperatures developed ginseng rust-spots but did not develop the white cell proliferations. The development of ginseng rust-spots on the controls may be due to factors imposed on the roots by the Pro-Mix-Bx which contains $70 \%$ peat. Yingping et al. ${ }^{5)}$ investigated the role that soil plays on the genesis of rust-spots and determined that the organic matter of the soil, and also the pore spaces present, have an effect on rust-spot development. Soil with a high amount of undecomposed organic matter resulted in the reduction of ferric ions to ferrous ions. Iron, in its reduced form, was positively correlated with the formation of rust-spots. The Pro-Mix-Bx has a higher organic matter content and therefore may increase the chance of rust-spot development.

The soil pore spaces also play a key role by providing the necessary environment for chemical processes to occur. The water holding pores provide the anaerobic environment necessary for the reduction of iron to its ferrous form. This suggests that if the water content of the Pro-Mix-Bx, which is $70 \%$ peat, was elevated then there would be a greater chance for the development of rust-spots.

In summary, these anatomical studies are the first report on the characterization of ginseng rust-spots of North American ginseng. The orange-brown sunken lesions are 
the result of the oxidization of phenolic compounds, confirming our earlier work ${ }^{6)}$ and are not caused by any pathological associations. Rust-spots affect the first 4-5 cell layers of the periderm. More severe spots may penetrate deeper into the roots affecting the pericycle and possibly the secondary phloem.

The cause(s) of this disorder must be determined so that effective control measures can be determined. The recent work on selection of biotic and abiotic preventers of the rusty phenomenon in ginseng roots is encouraging ${ }^{30}$. Examining how ginseng responds to mechanical and physiological stresses may help to predict when ginseng rustspot is a concern for growers. Growers will need to be more demanding in their site selection in relation to soil characteristics and nutrient balance. For instance, Asian work suggest that these sites must be well drained to avoid development of anaerobic environments conductive to the reduction of $\mathrm{Fe}^{3+}$ to $\mathrm{Fe}^{2+}$ (Yingping et al., 1997).

\section{ACKNOWLEDGEMENTS}

This research was supported in part by J.C.K. Farms Ltd. and the Ontario Ministry of Agriculture and Food. We are indebted to Lindsay Park and Dean Louttit for technical assistance.

\section{REFERENCES}

1. Parke, J. L. and Shotwell, K. M. : Diseases of cultivated ginseng. Univ. of Wisconsin: Ext. Res. Bul. 3465 (1989).

2. Brammall, R. A. : Rusted root (rusty root), p. 298. In: R.J. Howard, J.A. Garland, and W.L. Seaman (eds.). Diseases and Pests of Vegetable Crops in Canada: An illustrated compendium. Entomological Society of Canada, Ottawa. (1994).

3. Anonymous. : Ginseng pest control recommendations. Ontario Ministry of Agriculture, Food and Rural Affairs, Toronto. Ontario. Pub. 610 (1999-2000).

4. Reeleder, R. D. and Brammall, R. A. : Pathogenicity of Pythium species, Cylindrocarpon destructans, and Rhizoctonia solani to ginseng seedlings in Ontario. Can. J. Plant Pathol. 16, 311-316 (1994).

5. Yingping, W., Zhihong, L., Yanjun, S., Shiwei, G., Shuzhen, T. and Zhaorong, L. : Studies on genesis of ginseng rust spots. Korean J. Ginseng Sci. 21, 69-77 (1997).

6. Campeau, C., Proctor, J. T. A., Jackson, Chung-Ja C. and Vasantha Rupasinghe, H. P. : Rust-spotted North American ginseng roots: phenolic, antioxidant, ginsenoside and mineral nutrient content. HortScience 38, 179-182 (2003).

7. Lee, S. S., Lee, K. H. and Kim, E. S. : Mineral nutrition contents of rusty-root tolerance ginseng lines in 6-year old root.
J. Ginseng Res. 26, 159-164 (2002).

8. Mei, L., Jun, L. R. and Yuan, L. M. : The initiation and pattern of growth of resin ducts in the main roots of ginseng (Panax ginseng). Phytomorphology 40, 17-20 (1990).

9. Peterson, R. L., Varney, G. T. and Binns, S. : Structure of Panax quinquefolius L. (Araliaceae) roots with emphasis on secretory duct formation. J. Amer. Soc. Hort. Sci. 123, 798801 (1998).

10. Hiltunen, L. H. and White J. G. : Cavity spot of carrot (Daucus carota). Ann. Appl. Biol. 141, 201-223 (2002).

11. Link, G. K. K. and Gardner, M. W.: Market pathology and market disease of vegetables. Phytopathology 9, 497-520 (1919).

12. Ke, D. and Saltveit, M. E. : Plant hormone interaction and phenolic metabolism in the regulation of russet spotting in iceberg lettuce. Plant Physiol. 88, 1136-1140 (1988).

13. Ke, D. and Saltveit, M. E. : Developmental control of russet spotting, phenolic enzymes, and IAA oxidase in cultivars of iceberg lettuce. J. Amer. Soc. Hort. Sci. 114, 472-477 (1989a).

14. Ke, D. and Saltveit, M. E. : Regulation of russet spotting, phenolic metabolism, and IAA oxidase by low oxygen in iceberg lettuce. J. Amer. Soc. Hort. Sci. 114, 638-642 (1989b).

15. Rood, P. : Relation of ethylene and post-harvest temperature to brown spot of lettuce. Proc. Amer. Soc. Hort. Sci. 68, 296303 (1956).

16. Lee, S. S. : Phenolic compounds contents of rusty-root tolerance ginseng lines in 6-year old root. J. Ginseng Res. 26, 165-169 (2002).

17. Fiebig, A. E. : Inflorescence development of North American ginseng: abscission zones and ethephon. MSc diss., Univ. of Guelph, Ontario, Canada. (1999).

18. Fiebig, A. E., Proctor, J. T. A., Posluszny, U. and Murr, D. P. : The North American ginseng inflorescence: development, floret abscission zone, and the effect of ethylene. Can. J. Bot. 79, 1048-1056 (2001).

19. Proctor, J. T. A., Percival, D. and Louttit, D. : Inflorescence removal affects root yield of American ginseng. HortScience 34, 82-84 (1999).

20. Hawker, J. S., Buttrose, M. S., Soeffky, A. and Possingham, J. V. : A simple method for demonstrating macroscopically the location of polyphenolic compounds in grape berries. Vitis 11, 189-192 (1972).

21. Rost, F. W. D. : Flourescence microscopy. Cambridge University Press, New York. (1992).

22. Massicotte, H. B., Melville, L. H. and Peterson, R. L. : Scanning electron microscopy of ectomycorryhizae potential and limitations. Scanning Microscopy 1, 1439-1454 (1987).

23. Evans, I. R. and Howard, R. J. : Pink eye (brown eye) of potato, p. 229. In: R.J. Howard, J.A. Garland, and W.L. Seaman (eds.). Diseases and Pests of Vegetable Crops in Canada: An illustrated compendium. Entomological Society of 
Canada, Ottawa. (1994).

24. Bonello, P. and Pearce, R. B. : Biocinemical defense responses in primary roots of Scots pine challenged in vitro with Cylindrocarpon destructans. Plant Pathol. 42, 203-211 (1993).

25. Matuo, T. and Miyazawa, Y. : Scientific name of Cylindrocarpon sp. causing root rot of ginseng. Ann. Phytopath. Soc. Japan 50, 639-652 (1984).

26. Lipton, W. J. : Anatomical observations on russet spotting and pink rib of lettuce. J. Amer. Soc. Hort. Sci. 78, 367-374 (1961).

27. Hyodo, H., Kuroda, H. and Yang, S. F. : Induction of pheny- lalanine ammonia-lyase and increase in phenolics in lettuce leaves in relation to the development of russet spotting caused by ethylene. Plant Physiol. 62, 31-35 (1978).

28. Bennett, R. N. and Wallsgrove, R. M. : Secondary metabolites in plant defence mechanisms. New Phytol. 127, 617-633 (1994).

29. Abeles, F. : Ethylene in plant biology. $2^{\text {nd }}$ ed. Academic Press Inc., San Diego, California, (1992).

30. Ban, S. H., Shin, S. H., Woo, H. J., and Yang, D. C. : Selection of preventers of rusty ginseng roots from natural resources. J. Ginseng Res. 26, 89-95 (2000). 